\title{
QUANTITATIVE ESTIMATION OF RUTIN IN RUE (RUTA GRAVEOLENS L.) CULTIVATED IN IRAQ WITH THE EVALUATION OF ITS ANTIOXIDANT ACTIVITY
}

\author{
RASHA ELDALAWY* \\ Department of Pharmacognosy and Medicinal Plants, College of Pharmacy, AL-Mustansiriyah University, Baghdad, Iraq. \\ Email: rashaeldalawy@gmail.com
}

Received: 17 October 2016, Revised and Accepted: 26 October 2016

\begin{abstract}
Objective: This study was designed to estimate the quantity of the flavonoid glycoside (rutin) as an important active compound in rue plant grown in Iraq with the evaluation of its antioxidant activity.

Methods: The cultivated rue plant at the garden of medicinal plant in the pharmacognosy and medicinal plants department was collected and dried at room temperature. Total flavonoids content was determined using aluminum chloride method, and a standard calibration curve is used for estimation of rutin glycoside. Antioxidant activity of the ethanolic extract was measured using the (1,1-diphenyl-2-picrylhydrazyl radical).
\end{abstract}

Results: The results were showed that $100 \mathrm{~g}$ of the plant produced $7 \mathrm{~g}$ powdered extract, and each gram of the extract contains 133 mg rutin. The extract showed a positive antioxidant activity as compared with standard quercetin.

Conclusion: Ruta graveolens plant contains the flavonoid glycoside rutin which showed antioxidant activity; therefore, further studies are required to identify other constituents in this plant.

Keywords: Rue, Rutin, Flavonoids and antioxidant.

(C) 2017 The Authors. Published by Innovare Academic Sciences Pvt Ltd. This is an open access article under the CC BY license (http://creativecommons. org/licenses/by/4. 0/) DOI: http://dx.doi.org/10.22159/ajpcr.2017.v10i2.15726

\section{INTRODUCTION}

Oxidative metabolism is essential for cells survival, but it resulted in the formation of free radicals and other reactive oxygen species [1]. Increasing free radicals concentration in the body generates a phenomenon called oxidative stress, which will develop chronic and degenerative diseases such as autoimmune disorders, aging, cataract, rheumatoid arthritis, cancer, cardiovascular, and neurodegenerative diseases [2]. Many herbs have been identified as possessing antioxidative and anti-inflammatory properties, and they are currently being used to treat pathogens those caused by free radicals and reactive oxygen species [3]. Ruta graveolens L. shrubby plant, native to the Mediterranean region and present in traditional medicine of this region since decade [4]. $R$ graveolens is a flavonoid-containing medicinal plant with various biological properties [5]. In the present study, the plant has been cultivated in the medicinal plants garden of the College of Pharmacy/AlMustansiriyah University; then, it's flavonoid content, antioxidant activity, and the half maximum inhibitory concentration $\left(\mathrm{IC}_{50}\right)$ were evaluatefd.

\section{METHODS}

\section{Plant material}

R. graveolens was cultivated in the medicinal plants garden of the College of Pharmacy/Al-Mustansiriyah University then identified by National Herbarium of Iraq. Aerial parts were collected in March, washed with tap water to remove dust and dirt, dried in shade for 7 days then powdered by a grinder to obtain a powdered material.

\section{Plant extraction}

About $100 \mathrm{~g}$ of the pulverized plant was divided into two parts. Each part was extracted with $250 \mathrm{ml}$ of $70 \%$ ethanol in a Soxhlet apparatus for $72 \mathrm{hrs}$ each time; the whole ethanolic extracts were mixed and concentrated at reduced pressure using a rotary evaporator and stored in a refrigerator until further use.

\section{Estimation of total flavonoid content (TFC)}

TFC was determined according to the aluminum chloride colorimetric method; the ethanolic extract has been diluted with methanol to come under the linearity range $(2 \mathrm{ml}, 0.3 \mathrm{mg} / \mathrm{ml})$ then mixed with $0.1 \mathrm{ml}$ of $10 \% \mathrm{w} / \mathrm{v}$ aluminum chloride hexahydrate and $0.1 \mathrm{ml}$ of $1 \mathrm{M}$ potassium acetate and $2.8 \mathrm{ml}$ distilled water. After 40 minutes incubation period at room temperature, the sample was filtered through Whatman filter paper, then the absorbance of the reaction mixture was determined using ultraviolet (UV) apparatus at $415 \mathrm{~nm}$ with a double beam UVvisible spectrophotometer SHIMADZU UV 1800. A standard calibration curve is obtained from a series of different concentrations of standard rutin.

Determination of antioxidant activity (1,1-diphenyl-2 picrylhydrazyl radical [DPPH] free radical scavenging)

Antioxidant activity of the ethanolic extract was measured using the stable DPPH. $1 \mathrm{ml}$ of different concentrations of ethanolic extract was mixed with $5 \mathrm{ml}(100 \mu \mathrm{M})$ freshly prepared DPPH-methanol solution in a test tube, and the reaction mixture was set aside in the dark at room temperature for 30 minutes. Thereafter, the absorbance was recorded at $517 \mathrm{~nm}$. The antioxidant reacts with DPPH and gets reduced to DPPH-H form thereby decreasing in absorbance value. The percentage inhibition of DPPH radical was calculated by comparing the results of the test samples with those of the control (not treated with extract) using the following equation:

Percentage inhibition=(1-absorbance of test/absorbance of control) $\times 100$

$\mathrm{IC}_{50}$ which is the concentration of sample required to scavenge $50 \%$ of DPPH free radicals value have been calculated with a comparison to standard reference (Quercetin) from the graph of concentration versus $\%$ inhibition. 


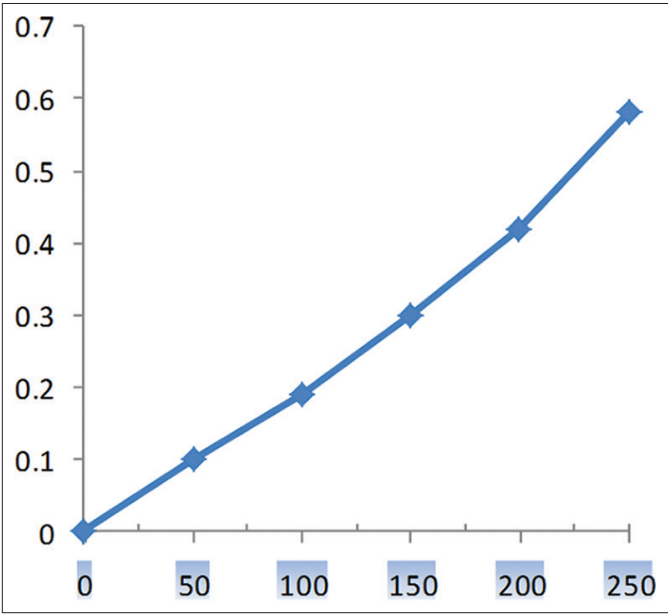

Fig. 1: Standard calibration curve of rutin

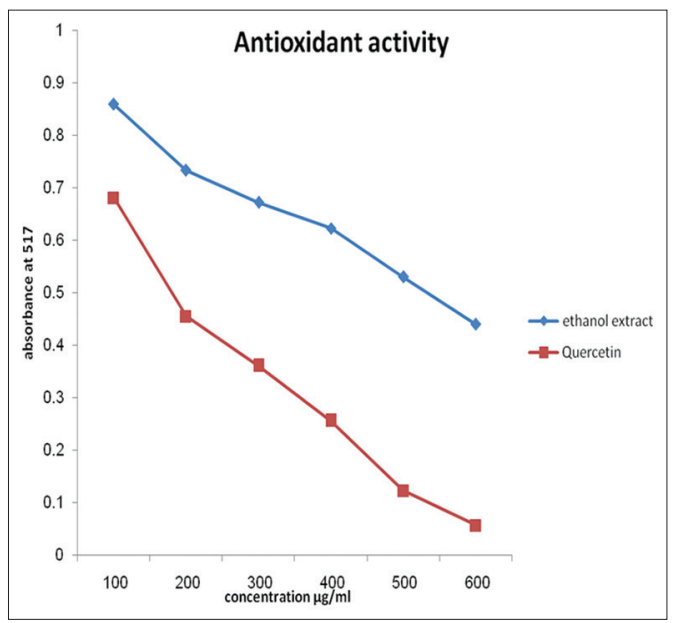

Fig. 2: Estimation of antioxidant activity by 1,1-diphenyl-2picrylhydrazyl radical method

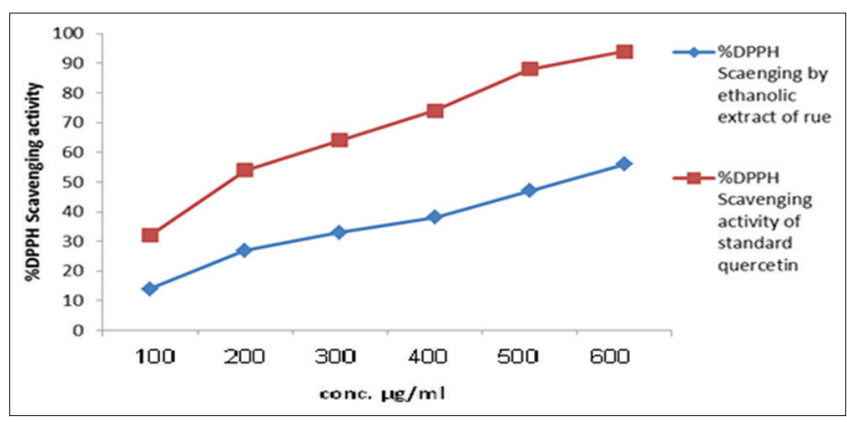

Fig. 3: Estimation of 1,1-diphenyl-2-picrylhydrazyl radical scavenging activity

\section{RESULTS AND DISCUSSION}

Flavonoids are the most important secondary plant phenolics with significant chelating and antioxidant properties. These compounds are based on the flavan nucleus, in which the number, positions, and types of substituent influence radical scavenging and chelating activity [6]. R. graveolens is rich in flavonoids and contains a high percent of the flavonoid glycoside rutin which is well known as antioxidant [7]. Aluminum chloride forms acid stable complexes with the C-4 keto group and either the C-3 OR C-5 hydroxyl group of flavones and flavonols, in addition, aluminum chloride form acid labile complexes

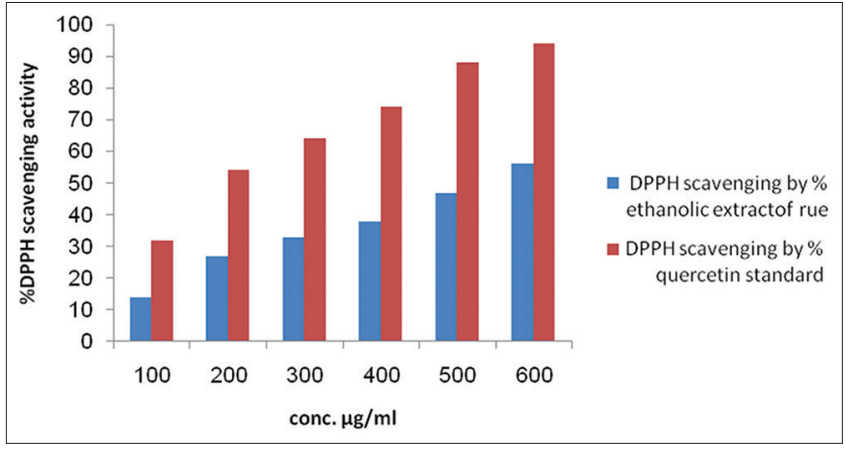

Fig. 4: Comparison of scavenging activity of extract versus standard quercetin

Table 1: The results of the calibration curve

\begin{tabular}{lll}
\hline Extract & Yield \% W/W & $\begin{array}{l}\text { TFC } \boldsymbol{\mu g} \text { of rutin/mg } \\
\text { of extract }\end{array}$ \\
\hline $\begin{array}{l}\text { Ethanolic extract of whole } \\
\text { aerial parts of rue }\end{array}$ & 7 & 133.3 \\
\hline TFC: Total flavonoid content & & \\
\hline
\end{tabular}

Table 2: DPPH radical scavenging activity

\begin{tabular}{lll}
\hline Concentration $(\boldsymbol{\mu g} / \mathbf{m l})$ & $\begin{array}{l}\text { Absorbance at } \mathbf{5 1 7} \\
\text { ethanolic extract of rue }\end{array}$ & $\begin{array}{l}\text { Quercetin } \\
\text { standard }\end{array}$ \\
\hline 100 & 0.859 & 0.681 \\
200 & 0.733 & 0.455 \\
300 & 0.672 & 0.361 \\
400 & 0.623 & 0.256 \\
500 & 0.530 & 0.123 \\
600 & 0.440 & 0.057 \\
\hline
\end{tabular}

DPPH: 1,1-diphenyl-2-picrylhydrazyl radical

with orthodihydroxyl groups in the A- or B-ring of flavonoids [8]. The ethanolic extract of the whole aerial parts was prepared, and their TFC was calculated with respect to standard rutin (Fig. 1 and Table 1).

DPPH free radical scavenging method was used because it is an easy, rapid, and sensitive way to survey the antioxidant activity of the plant extract [9]. Quercetin used as standard in this method since quercetin is considered to be a strong antioxidant due to its ability to scavenge free radicals and bind transition metal ions [10]. The results of DPPH free radical scavenging were presented in Table 2, Figs. 2-4.

$\mathrm{IC}_{50}$ calculated from the figure is $540 \mu \mathrm{g} / \mathrm{ml}$ for $R$ graveolens whole aerial parts ethanolic extract.

\section{CONCLUSION}

$R$. graveolens L. contains the flavonoids glycoside such as rutin compound, which known to have antioxidant, anti-inflammatory, and antirheumatic activities. The extract of the plant may be used to treat various diseases. Further studies are required to identify other constituents in this plant.

\section{REFERENCES}

1. Michael A, Prenzler PD, Emilios P, Suzanne M, Kevin R. Methods for testing antioxidant activity. Analyst 2002;127(1):183-98.

2. Lien A, Hua H, Chuong P. Free radicals, antioxidants in disease and health. Int J Biomed Sci 2008;4(2):89-96.

3. Mitchell K, Ece AM, Mark B, Jeremy ZF, Ali B, Ali K. Use of herbal in the treatment of oxidant-mediated inflammatory disorders. Complement Ther Med 2007;15(3):207-16.

4. Pollio A, De Natale A, Appetiti E, Aliotta G, Touwaide A. Continuity 
and change in the Mediterranean medical tradition: Ruta spp. (Rutaceae) in Hippocratic medicine and present practices. J Ethnopharmacol 2008;116(3):469-82.

5. Pirouzpanah S, Rashidi MR, Delazar A, Razavieh SV, Hamid A. Inhibitory effects of Ruta graveolens L. Extract on guinea pig liver aldehyde oxidase. Chem Pharm Bull (Tokyo)

6. Boob, \$4A(1) AgthBny R, Tagliaferro D, Bobilya J. Flavonoid antioxidants: Chemistry, metabolism and structure-activity relationships. J Nutr Biochem 2002;13(10):572-84.

7. Sofic E, Cobra-Janicijevic A, Salehovic M, Kroyer G. Screening of medicinal plant extracts for quercetin-3-rutinoside (rutin) in Bosnia and Herzegovina. Med Plants 2010;2(2):97-102.

8. Chia-Chi C, Ming-Hua Y, Hwei-Mei W, Jiing-Chuan C. Estimation of total flavonoid content in propolis by two complementary colorimetric methods. J Food Drug Anal 2002;10(3):178-82.

9. Pourmorad F, Hosseinimehr SJ, Shahabimajd N. Antioxidant activity, phenol and flavonoid contents of some selected Iranian medicinal plants. Afr J Biotechnol 2006;5(11):1142-5

10. Sudjarwo SA. Mechanism of endothelial cell protection by quercetin in hypercholesterolemia. Res Pharm Biotechnol 2011;3(9):123-7. 